\title{
Burden of disease due to dementia in the elderly population of Korea: present and future
}

Jae-Hyun Park ${ }^{1,2}$, Jin-Hee Eum ${ }^{1}$, Bolor Bold ${ }^{1}$ and Hae-Kwan Cheong ${ }^{1,2^{*}}$

\begin{abstract}
Background: With the rapid aging of populations around the world, dementia has become one of the most important public health problems in Eastern Asian countries. The purpose of the present study was to provide an estimate of the burden of dementia and forecast its future burden, as generalized to the Korean population, and to provide detailed gender- and age-specific information regarding the burden of dementia in the elderly population of Korea.

Methods: 'Disability-adjusted life years' (DALYs) were used to estimate the burden of dementia. Epidemiologic data from national statistics and nationwide epidemiologic studies in the year 2008 were used to obtain representative outcomes for the Korean population. We estimated the DALYs due to dementia from the years 2010 to 2050 by applying demographic structure projections in terms of 5 -year age groups in Korea.

Results: The burden of disease due to dementia in Korea is 528 per 100,000 population (males: 435, females: 622) and 5,117 per 100,000 in those over the age of 65 years (males: 5,228; females: 5,041); this accounts for 4.5\% of the total burden of disease in the year 2008. In the year 2050, DALYs due to dementia $(814,629)$ are expected to be 3.0 times higher than those in the year $2010(274,849)$.

Conclusion: Dementia has the highest burden of disease in the elderly Korean population, and this burden will increase sharply with the aging of the population. More comprehensive and multi-dimensional approaches, including clinical, psychological, social, and political means will be needed for the management of the dramatically increasing burden of dementia.
\end{abstract}

Keywords: Dementia, Burden of disease, DALY, Alzheimer's disease

\section{Background}

Dementia generally occurs in the elderly and is one of the most serious mental illnesses in the Korean population [1]. Given its progressive, irreversible natural course, together with its high prevalence in the elderly population, dementia has one of the biggest burdens of disease in the elderly $[2,3]$. As the world's population is rapidly aging, dementia has become an important public health problem $[4,5]$. The World Health Organization (WHO) has estimated dementia to be the 11th leading cause of years lived with disability (YLD) at a global level, accounting for $2.0 \%$ of the total global YLDs [6]. By the year 2050, the worldwide

\footnotetext{
* Correspondence: hkcheong@skku.edu

'Department of Social and Preventive Medicine, Sungkyunkwan University School of Medicine, 2066 Seobu-ro, Jangan-gu, Suwon, Gyeonggi-do 440-746, Republic of Korea

${ }^{2}$ Center for Molecular Medicine, Samsung Biomedical Research Institute, Seoul, Republic of Korea
}

prevalence of dementia will quadruple to 106.2 million persons, with 1 in 85 persons living with Alzheimer's disease [7]. Specifically, dementia is expected to become a more of a serious health and social burden in developing countries than in developed countries. This is because unprecedented declines in mortality and fertility have resulted in a rapid aging process in most developing countries [8], which is exacerbated by poor health care facilities.

To estimate the burden of diseases, the WHO recommends using disability-adjusted life years (DALYs) [9]. DALYs have the merit of simplicity and comprehensiveness, as its calculation produces a single number that combines information on mortality and non-fatal health outcomes. According to the Global Burden of Disease (GBD) estimates from the 2003 World Health Report [10], dementia contributed $11.2 \%$ of the YLD in people aged 60 years and older. This is more than stroke (9.5\%), 
musculoskeletal disorders (8.9\%), cardiovascular disease (5.0\%), and all forms of cancer (2.4\%).

These estimates have limitations because of the lack of accurate epidemiologic data, especially in developing countries [7]. In 2003, the World Health Report addressed dementia in many world regions; however, such evidence suffers from incompleteness or is limited in coverage. Even when a wider evidence base is available for countryor region-specific figures, these estimates are sometimes generated from a single study with limited generalization. Previous global estimates of the number of people with dementia have tended to apply a uniform age-specific prevalence, assuming no geographic variation [11,12]. However, prevalence has been noted to be lower in developing countries [13], strikingly so in some studies [14,15].

Korea represents an unique situation in terms of the burden of dementia. Korea has a population of over 49 million people. Its life expectancy at birth has increased dramatically in recent years (71.3 in 1990, 78.6 in 2000, and 80.8 in 2010 [16]. The country is in the midst of a rapid transition from being a low-income country to becoming a high-income country, and its population structure is aging at an unprecedented speed [16]. The proportion of the elderly population reached $7.2 \%$ in 2000 and is expected to exceed $14 \%$ by 2018 , and $20.8 \%$ by 2026; one of the fastest transitions from an aging society to an ultra-aged society. Therefore, changes in the burden of disease due to dementia in Korea may represent a typical situation that will be experienced in many developing countries in the near future.

A previous WHO study [17] estimated the burden of dementia in Korea using several epidemiologic indices adopted from other countries. These indices included incidence and relative risk of mortality from European countries, where prevalence was consistent with literature for Chinese populations due to the lack of epidemiologic data from the Korean population. However, a recent study [18] also did not use epidemiologic data produced in the Korean population, but used meta-analysis results from other high-income Asia Pacific countries instead. As such, there is a critical need for a study to estimate the burden of dementia using Korean-specific epidemiologic data.

This study was conducted to provide an estimate of the burden of dementia in the elderly and to forecast it for the future to provide detailed gender- and age-specific estimates of the burden of dementia using the most recent epidemiologic data from the Korean population.

\section{Methods}

\section{Data source and epidemiologic data}

DALYs due to dementia were calculated using various epidemiologic data such as incidence, prevalence, remission rate, case mortality, age of onset, disease duration, disability weight, total mortality of the population, and population structure. All the data were derived from various epidemiologic studies conducted in Korea and from a Korean national dataset [19]. This previous nationwide population study carried out in 2008 was based on 8,199 probability-sampled Koreans aged 65 years or older. The study used a 2-step assessment method to identify persons with dementia: 1) All the sampled individuals were invited to participate in the Phase I screening assessment using the Mini-Mental State Examination via door-to-door home visits, and 2) the Phase II diagnostic assessment for dementia was administered using the Korean version of the Consortium to Establish a Registry for Alzheimer's Disease Assessment Packet (CERAD-K) clinical assessment battery, neuroimaging, including computed tomography or magnetic resonance imaging (MRI), and laboratory testing. Patients were diagnosed with dementia using the criteria established in the Diagnostic and Statistical Manual, 4th Revision (DSM-IV), or with Alzheimer's disease according to the criteria of the National Institute of Neurological and Communicative Disorders and Stroke and the Alzheimer's Disease and Related Disorders Association (NINCDSADRDA), or with vascular dementia according to the criteria of the National Institute of Neurologic Disorders and Stroke/Association Internationale pour la Recherche et l'Enseignement en Neurosciences (NINDS-AIREN) [19]. We adopted gender- and age-specific prevalence of dementia for this study from the published article [19] and report [20]. As the previous report used a sample aged 65 years or older, we also adopted the prevalence of dementia in adults aged 65 years or older. Case mortality due to dementia and total mortality of the population by gender and age group were derived from cause of death statistics from Statistics Korea [21]. In Korea, the cause of death on the death certificate must, by law, be decided by a doctor. Therefore, Korea has a relatively comprehensive and accurate death certification system. The population structure of each gender and age group in 2008 was derived from baseline population estimates from Statistics Korea [16]. These datasets from Statistics Korea are public data sources and completely open to the public with free website access $[16,21]$. Other parameters for the estimation of the burden of disease, including incidence, disease duration, and age of onset, were estimated with DISMOD-II software [22], using prevalence, remission rate, case mortality, total population, and total mortality. DISMOD II, developed by WHO for the GBD project, is a software program that can be used to estimate missing parameters and to verify the consistency of the estimates for diseases [23]. The remission rate was assumed to be zero. The disability weight of 0.911 was derived from the results in the previous Korean panel study [24].

\section{DALY calculation and projection}

In general, this study followed the protocols of the original GBD study [25]. DALYs are the sum of two components. 
The first, Years of Life Lost (YLLs), measures the number of years lost when a person dies prematurely. The second component, Years Lived with Disability measures the number of years of healthy life lost due to temporary or permanent disability. YLL estimates were derived from mortality and life expectancy at birth in 2008 [26]. YLD estimates were derived from incidence, mortality, disease duration, and age of onset from the DISMOD II output. YLL, YLD and DALY estimates were calculated according to gender and 5-year age groups. We forecasted the DALYs due to dementia in the years 2010-2050 by applying demographic structure projections and assuming a constant age-specific prevalence of dementia [27].

\section{Results}

\section{Results of DISMOD II modeling}

Input variables in the DISMOD II model (prevalence, dementia mortality, remission rate, population and overall mortality) and output variables in the year 2008 generated from the model are illustrated in Table 1. Comparing input and output variables in terms of prevalence we did not find any discrepancies; this implies consistency of estimates for the diseases. Incidence demonstrated its peak at the ages of 80-84 and subsequently decreased. Case mortality showed a gradually increasing pattern in both genders. Incidence, prevalence, mortality, duration, and age of onset outputs shown in Table 1 were used in the YLD calculation. Mortality due to dementia from the DISMOD II output was used in the YLL calculation.

\section{YLLs, YLDs, and DALYs due to dementia}

YLLs, YLDs, and DALYs in the year 2008 due to dementia in the elderly in Korea were 24,344, 232,303, and 256,647 person-years, respectively (Table 2). The burden of dementia was highest in the age group of 65-69 years (Table 2, Figure 1). YLLs, YLDs, and DALYs due to dementia were calculated per 100,000 in each age group and are listed in Table 2 and Figure 2. In total, the YLLs, YLDs, and DALYs in 2008 due to dementia per 100,000 were 50, 478, and 528 person-years, respectively. When projected to the general population, the burden of disease due to dementia per 100,000 was 435 person-years in males and 622 personyears in females in 2008. In the population aged 65 years or older, the burden of dementia was 5,117 person-years per 100,000 (males: 5,228 person-years, females: 5,041 person-years) in 2008.

DALYs due to dementia projected from the years 2010-2050 DALYs due to dementia projected from the years 2010 to 2050 are illustrated in Figure 3. In both males and females, DALYs due to dementia were expected to show a continuous increase. In 2050, DALYs due to dementia $(814,629$ person-years) are expected to be 3.0 times higher than those in the year 2010 (274,849 person-years).

\section{Discussion}

In this study, we estimated the burden of disease due to dementia in Korea as 528 per 100,000, which accounts for $4.5 \%$ of the total burden of disease in Korea in the year 2008. WHO previously estimated the burden of disease due to dementia in Korea as 222 per 100,000 in the year 2004 [28]. This accounted for $1.7 \%$ of the total burden of disease in Korea which is less than half of the result reported in this study. This gap is derived from differences in the epidemiologic data used in the studies. The WHO study estimated the burden of dementia in Korea based on the fact that Korea belongs to the Western Pacific Regional Office (WPRO) B1, which includes China [17]. The WHO study also used overall weighted prevalence of dementia of $3.54 \%$ (male) and $4.45 \%$ (female) in calculating the DALYs in the WPRO B1 region. However, the prevalence of dementia used in this study was around $8.1 \%$ in 2008 , which is also higher than the results of another recent study in which the standardized prevalence for adults aged 60 years and over is 6.3\%) [18]. As addressed in the methods section, the prevalence of dementia used in this study was derived from the most recent study using a representative nationwide sample of elderly Koreans [19]. In addition, Korea is one of the most aged societies in the WPRO B1 region and shows the most rapid rate of aging among developing countries [29]. Previous studies have shown that the prevalence of dementia among the elderly ranges from $3.6-11.9 \%$ in Western countries [30-36] and $4.8-7.2 \%$ in Japan [37-40], which is a similar or lower prevalence compared to that of Korea. These facts could explain Korea's high burden of dementia.

This study and the previous WHO study also differed in their disability weight of dementia used in the DALY calculation. In this study, we used the disability weight of 0.911, which was 1.46 times higher than the disability weight of 0.625 used in the WHO study [17]. Whereas disability weights in the WHO study were greatly influenced by developed Western countries, the disability weights in this study were derived from a study conducted in Korea, reflecting psychosocial circumstances specific to the country of study [24]. This gap, in part, explains the higher DALY in this study compared with the WHO study.

Regarding the incidence and prevalence rates of dementia used in the DALY calculation in this study, increasing trends with increasing age in this study correspond with previous study results. Several previous studies $[7,41,42]$ have reported that the doubling time of incidence and prevalence of dementia was approximately 5 years. In this study, the incidence and prevalence of dementia increased to almost double as age increased by 5 years, until the ages of $85-89$ years. Above the age of 90 years, the rates of increase slowed and subsequently decreased. In a previous study [8], the increasing 
Table 1 Input and Output Variables in the DISMOD II Model (year 2008)

\begin{tabular}{|c|c|c|c|c|c|c|c|c|c|c|c|c|c|c|c|c|c|c|}
\hline \multirow[t]{3}{*}{ Age group } & \multicolumn{8}{|c|}{ Input } & \multicolumn{10}{|c|}{ Output } \\
\hline & \multicolumn{2}{|c|}{ Prevalence $^{\ddagger}$} & \multicolumn{2}{|c|}{ Dementia mortality $^{*}$} & \multicolumn{2}{|c|}{ Population $^{* *}$} & \multicolumn{2}{|c|}{ Mortality $^{*}$} & \multicolumn{2}{|c|}{ Incidence } & \multicolumn{2}{|c|}{ Prevalence } & \multicolumn{2}{|c|}{ Mortality } & \multicolumn{2}{|c|}{ Duration (yr) } & \multicolumn{2}{|c|}{ Age of onset (yr) } \\
\hline & Men & Women & Men & Women & Men & Women & Men & Women & Men & Women & Men & Women & Men & Women & Men & Women & Men & Women \\
\hline $65-69$ & 0.0352 & 0.0307 & 0.0001 & 0.0001 & 829,526 & 987,096 & 0.0199 & 0.0077 & 0.0077 & 0.0062 & 0.0194 & 0.0171 & 0.0010 & 0.0003 & 12.61 & 16.69 & 67.85 & 67.85 \\
\hline 70-74 & 0.0571 & 0.0436 & 0.0004 & 0.0003 & 610,634 & 825,685 & 0.0341 & 0.0150 & 0.0099 & 0.0078 & 0.0609 & 0.0517 & 0.0005 & 0.0003 & 10.99 & 13.73 & 72.45 & 72.44 \\
\hline $75-79$ & 0.1204 & 0.1152 & 0.0009 & 0.0010 & 345,459 & 590,729 & 0.0564 & 0.0298 & 0.0177 & 0.0135 & 0.1146 & 0.0936 & 0.0008 & 0.0008 & 8.20 & 10.06 & 77.85 & 77.86 \\
\hline $80-84$ & 0.2163 & 0.1628 & 0.0029 & 0.0031 & 163,459 & 345,906 & 0.0968 & 0.0585 & 0.0280 & 0.0278 & 0.2098 & 0.1759 & 0.0023 & 0.0025 & 6.32 & 7.46 & 82.43 & 82.64 \\
\hline 85-89 & 0.2698 & 0.2871 & 0.0070 & 0.0077 & 65,151 & 167,598 & 0.1592 & 0.1087 & 0.0172 & 0.0303 & 0.2850 & 0.2787 & 0.0058 & 0.0067 & 5.29 & 5.73 & 87.13 & 87.31 \\
\hline $90+$ & 0.2698 & 0.2871 & 0.0128 & 0.0153 & 17,951 & 66,832 & 0.2437 & 0.1992 & 0.0080 & 0.0108 & 0.2818 & 0.3064 & 0.0118 & 0.0143 & 4.53 & 3.87 & 99.71 & 97.06 \\
\hline
\end{tabular}

¥Kim KW et al. [19], *Statistics Korea [21], **Statistics Korea [16]. 
Table 2 YLL, YLD, and DALY due to Dementia in Korea (year 2008)

\begin{tabular}{|c|c|c|c|c|c|c|c|c|c|c|c|c|c|c|c|c|c|c|}
\hline \multirow{2}{*}{$\begin{array}{l}\text { Age } \\
\text { group }\end{array}$} & \multicolumn{3}{|c|}{ Men } & \multicolumn{3}{|c|}{ Women } & \multicolumn{3}{|c|}{ Total } & \multicolumn{3}{|c|}{ Men (per 100,000 people) } & \multicolumn{3}{|c|}{ Women (per 100,000 people) } & \multicolumn{3}{|c|}{ Total (per 100,000 people) } \\
\hline & YLL & YLD & DALY & YLL & YLD & DALY & YLL & YLD & DALY & YLL & YLD & DALY & YLL & YLD & DALY & YLL & YLD & DALY \\
\hline $65-69$ & 6,377 & 38,325 & 44,703 & 3,065 & 43,817 & 46,882 & 9,442 & 82,142 & 91,585 & 655 & 3,934 & 5,389 & 311 & 4,439 & 4,749 & 520 & 4,522 & 5,041 \\
\hline 70-74 & 1,663 & 28,061 & 29,725 & 1,595 & 35,221 & 36,815 & 3,258 & 63,282 & 66,540 & 201 & 3,383 & 4,868 & 193 & 4,266 & 4,459 & 227 & 4,406 & 4,633 \\
\hline $75-79$ & 1,152 & 18,328 & 19,480 & 2,197 & 28,563 & 30,761 & 3,349 & 46,892 & 50,241 & 189 & 3,002 & 5,639 & 372 & 4,835 & 5,207 & 358 & 5,009 & 5,367 \\
\hline 80-84 & 1,039 & 8,823 & 9,862 & 2,888 & 21,870 & 24,757 & 3,927 & 30,693 & 34,620 & 301 & 2,554 & 6,034 & 835 & 6,322 & 7,157 & 771 & 6,026 & 6,797 \\
\hline $85-89$ & 684 & 1,477 & 2,161 & 2,457 & 7,179 & 9,636 & 3,141 & 8,656 & 11,797 & 418 & 904 & 3,317 & 1,466 & 4,283 & 5,750 & 1,350 & 3,719 & 5,069 \\
\hline $90+$ & 201 & 114 & 315 & 1,026 & 524 & 1,549 & 1,227 & 638 & 1,864 & 308 & 175 & 1,754 & 1,535 & 784 & 2,318 & 1,447 & 752 & 2,199 \\
\hline Total & 11,116 & 95,130 & 106,246 & 13,228 & 137,174 & 150,401 & 24,344 & 232,303 & 256,647 & 46 & 390 & 435 & 55 & 567 & 622 & 50 & 478 & 528 \\
\hline $65 \leq$ & 11,116 & 95,130 & 106,246 & 13,228 & 137,174 & 150,401 & 24,344 & 232,303 & 256,647 & 547 & 4,681 & 5,228 & 443 & 4,597 & 5,041 & 485 & 4,631 & 5,117 \\
\hline
\end{tabular}

YLL: years of life lost, YLD: years lived with disability, DALY: disability-adjusted life years. 


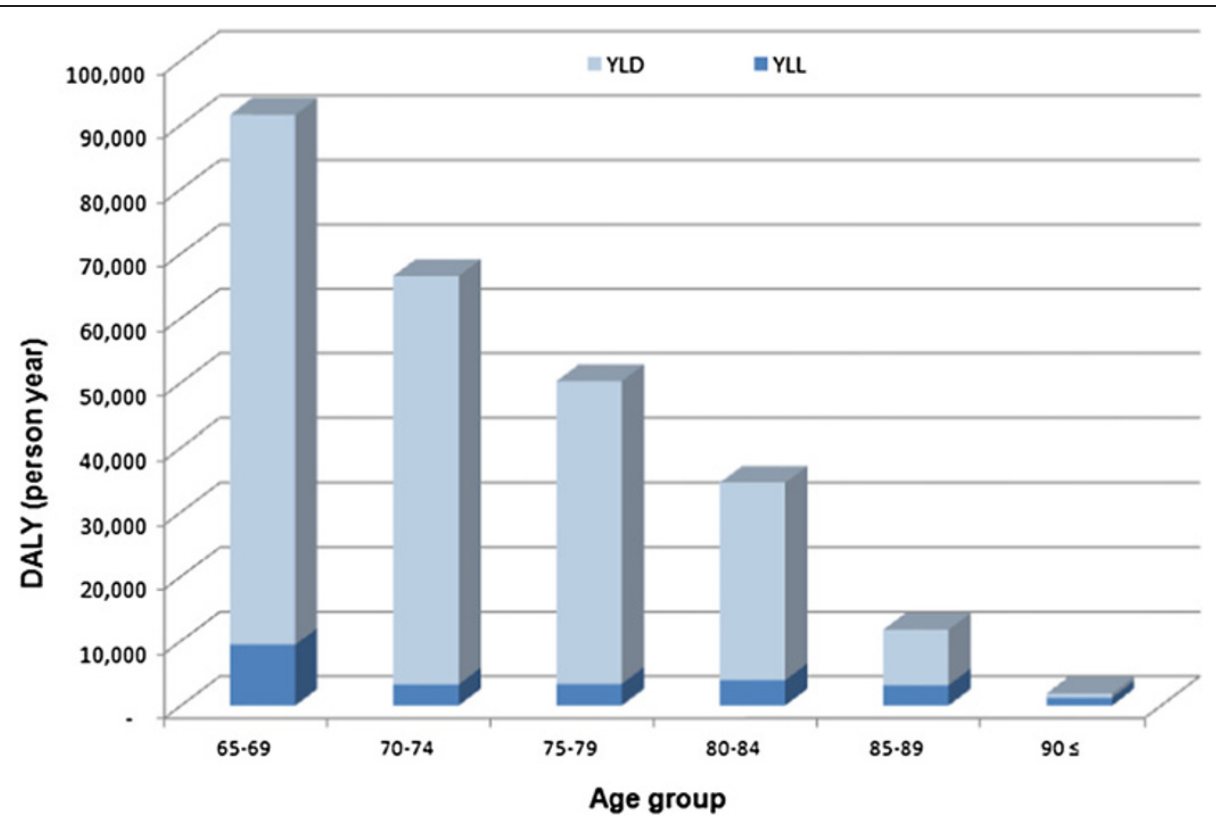

Figure 1 YLL, YLD, and DALY due to dementia in Korea (2008). YLL: years of life lost, YLD: years lived with disability, DALY: disability-adjusted life years.

occurrence of dementia appeared to curtail at age 85 and reached a plateau in people aged 85 years and older. This finding may relate to the difficulty in studying samples of individuals aged 90 years and older; the degree of diagnostic difficulty increases with age. These findings resulted in the increasing trend of DALY up to the age of 80 years followed by a decrease in DALY. However, even though we could not obtain an accurate level of incidence or prevalence of dementia in people aged 8090 years and older, the population in that age group is relatively small; therefore a more accurate estimation of DALYs due to dementia may not significantly influence the overall figure.

The 274,849 DALYs due to dementia in 2010 will rise to 814,629 DALYs in 2050, a 3.0-fold increase. This increase could in part be explained by the rapidly aging

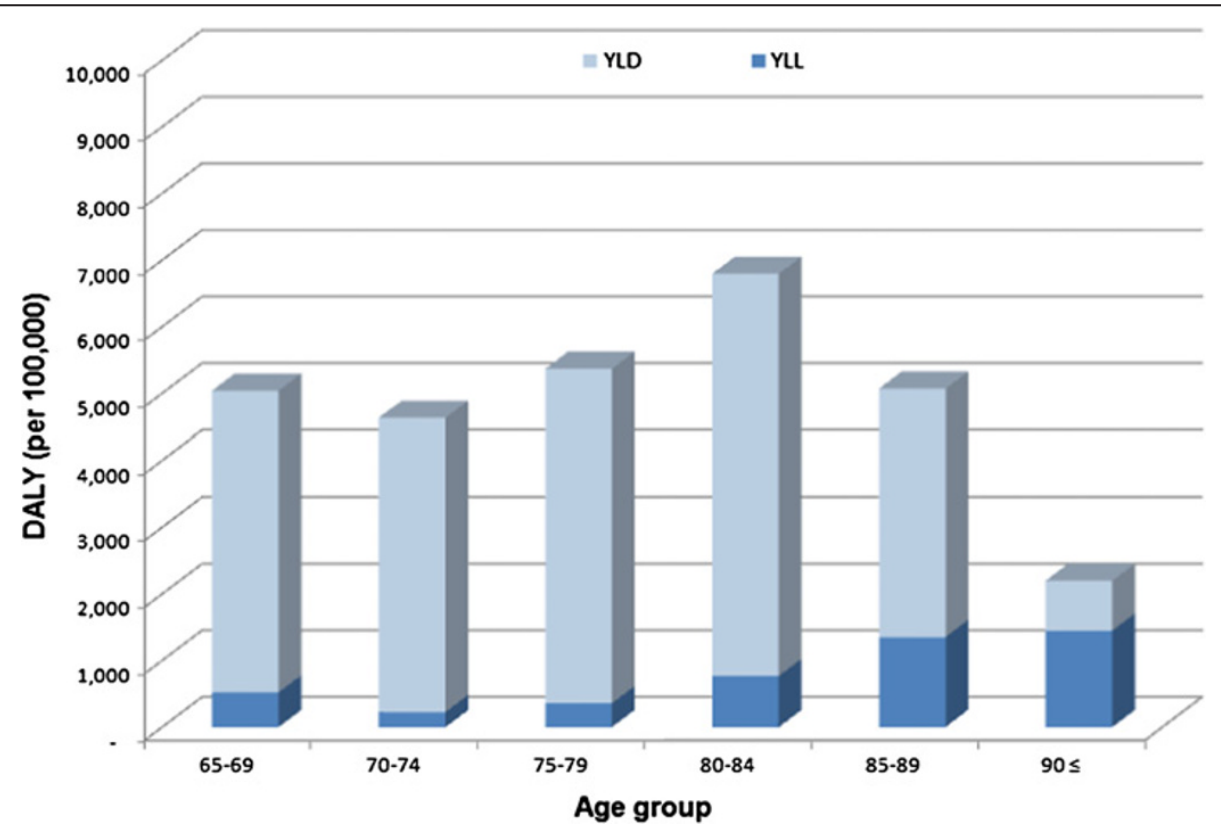

Figure 2 YLL, YLD, and DALY due to dementia in Korea (2008) (per 100,000 in each age group). YLL: years of life lost, YLD: years lived with disability, DALY: disability-adjusted life years. 


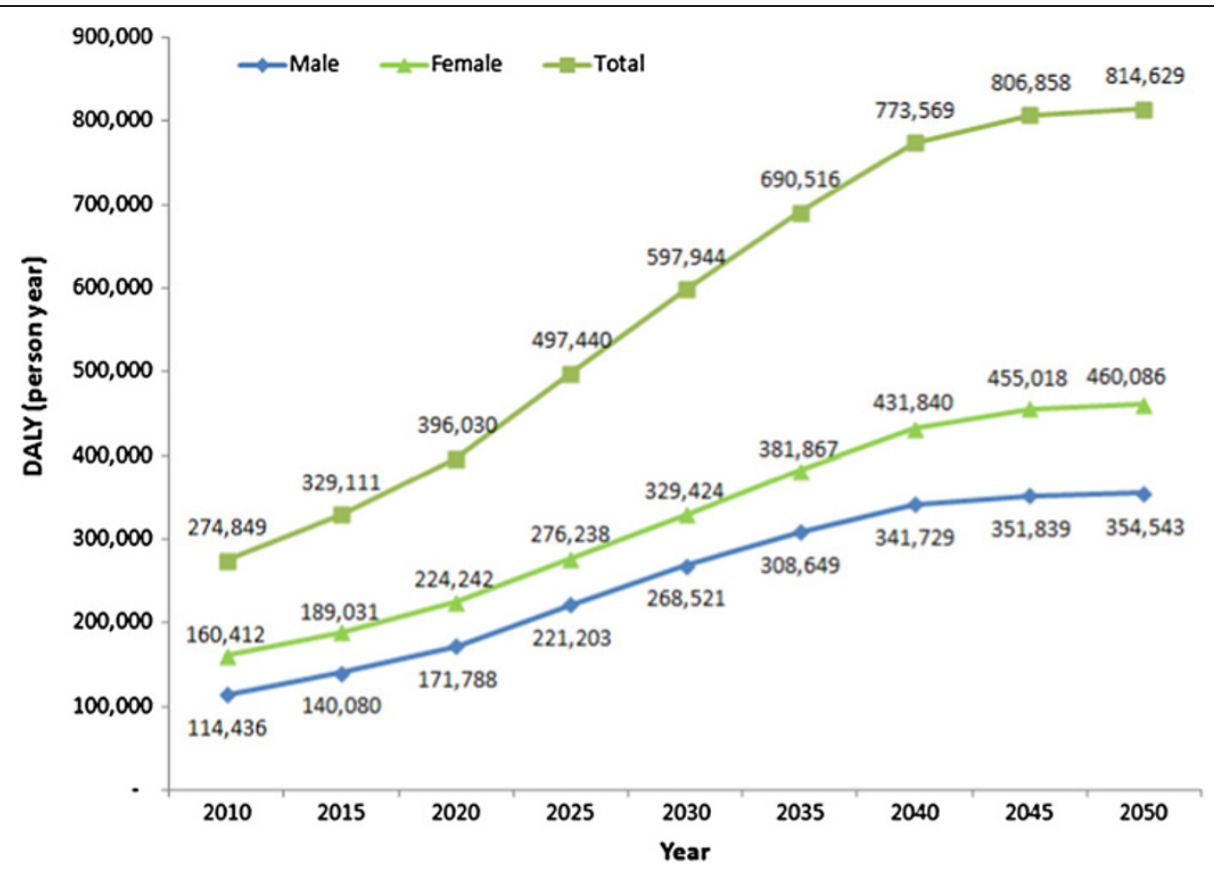

Figure 3 DALYs due to dementia projected from the years 2010 to 2050 in Korea. DALY: disability-adjusted life years.

population in Korea [29]. It also indicates that other developing countries shall face a tremendous increase in the burden due to dementia in the near future. Previous reports have also forecasted that the burden of dementia will become more serious in developing countries than in developed countries because unprecedented declines in mortality and fertility have resulted in a rapidly aging population in most developing countries [8]. This forecast provides us with important insight regarding health and welfare service systems in developing countries. Previously, most developing countries have focused on communicable diseases and some chronic diseases as the major health problems. These countries should now prepare to manage diseases like dementia, which hamper the quality of life and autonomy of older people. This will require the redesign of national health and welfare service systems in developing countries.

This study has several limitations. First, because of the lack of more detailed epidemiologic information, we could not distinguish the severity of dementia and, as such, could not estimate DALYs according to disease severity level. The resources needed to care for dementia patients depend on the stage of the disease. Adult daycare programs may be adequate in the early stages, while a high level of care, equivalent to that in nursing homes, will be needed in the late stages [7]. Second, we could not distinguish the type of dementia, i.e., vascular dementia $(\mathrm{VaD})$ vs. Alzheimer's disease (AD). Even though there is a small difference regarding the quality of life or autonomy due to the type of dementia, the risk factors are different in each type, meaning different strategies for prevention are necessary. According to previous studies, the ratio of $\mathrm{VaD}$ to $\mathrm{AD}$ has shown a wide variation, ranging from 1:1.5 - 1:7 according to the country. In Asian countries, the ratio of $\mathrm{VaD}$ to $\mathrm{AD}$ is around 1:1.5. Most recent studies in Korea have reported a ratio up to $1: 3[18,42]$, demonstrating that the epidemiology of dementia in Korea is approaching that of Western countries. These different types of dementia might manifest as different levels of DALYs. However, because $\mathrm{VaD}$ and $\mathrm{AD}$ share similar levels of deterioration in quality of life and autonomy, the different types of dementia should not impose substantial inaccuracies in the DALY calculation. Third, in projecting the burden of dementia, we assumed that the age-specific prevalence of dementia would remain constant over time. In fact, changes in risk exposure may increase or decrease the incidence. Improved medical and social care might reduce case mortality and increase prevalence. Interventions that delay onset would have substantial potential for reducing age-specific prevalence $[7,29,43]$. In light of these points, the future burden of dementia is expected to be different compared to that found in this study.

Despite these limitations, we believe that the detailed estimates contained in this paper provide the best currently available basis for policymaking, planning, and allocation of health and welfare resources for the management of dementia. To tackle these problems, continuous monitoring of the burden of disease due to dementia should be conducted from this point forward. Raising awareness and creating a framework for positive engagement between 
policymakers, clinicians, researchers, caregivers, and people with dementia will be needed in the near future.

\section{Conclusion}

The burden of disease due to dementia in Korea is 528 per 100,000 population (males: 435, females: 622), and 5,117 per 100,000 in those over the age of 65 years (males: 5,228; females: 5,041). This accounts for $4.5 \%$ of the total burden of disease in the year 2008. In the year 2050, DALYs due to dementia $(814,629)$ are expected to be 3.0 times higher than that in the year $2010(274,849)$. This indicates that Korea shall face a tremendous increase in the burden due to dementia in the near future. This forecast provides us with important insight regarding health and welfare service systems in developing countries as well. Redesign of national health and welfare service systems in developing countries including Korea will be required in the near future.

\begin{abstract}
Abbreviations
AD: Alzheimer's disease; CERAD-K: Korean version of the Consortium to Establish a Registry for Alzheimer's Disease Assessment Packet;

DALY: Disability-adjusted life years; DSM-IV: Diagnostic and Statistical Manual, 4th Revision; GBD: Global burden of disease; MRI: Magnetic resonance imaging; NINCDS-ADRDA: National Institute of Neurological and Communicative Disorders and Stroke and the Alzheimer's Disease and Related Disorders Association; NINDS-AIREN: National Institute of Neurologic Disorders and Stroke/Association Internationale pour la Recherche et I'Enseignement en Neurosciences; VaD: Vascular dementia; WHO: World Health Organization; WPRO: Western Pacific Regional Office of World Health Organization; YLD: Years lived with disability; YLL: Years of life lost.
\end{abstract}

\section{Competing interests}

The authors declare that they have no competing interests.

\section{Authors' contributions}

JHP prepared the manuscript and reviewed all the data and results. JHE and BB collected and analyzed the data, prepared tables and figures, and conducted reference work. HKC designed and participated in reviewing the data analysis, preparing the paper and finalizing the manuscript. All authors reviewed and were involved in the preparation and finalization of the manuscript. All authors read and approved the final manuscript.

\section{Acknowledgements}

This study was supported by a grant from the Korea Health 21 R\&D Project of the Ministry of Health and Welfare, Republic of Korea (A050079), which supports a 5-year project of the Clinical Research Center for Dementia (CRCD or CREDOS).

Received: 9 October 2012 Accepted: 27 March 2013

Published: 3 April 2013

\section{References}

1. Guehne U, Riedel-Heller S, Angermeyer MC: Mortality in dementia. Neuroepidemiology 2005, 25:153-162.

2. Schneider J, Murray J, Banerjee S, Mann A: EUROCARE: a cross-national study of co-resident spouse carers for people with Alzheimer's disease: I - Factors associated with carer burden. Int J Geriatr Psychiatry 1999, 14:651-661.

3. Prince M, 10/66 Dementia Research Group: Care arrangements for people with dementia in developing countries. Int J Geriatr Psychiatry 2004, 19:170-177.

4. Agüero-Torres H, Fratiglioni L, Guo Z, Viitanen M, Winblad B: Prognostic factors in very old demented adults: a seven-year follow-up from a population-based survey in Stockholm. J Am Geriatr Soc 1998, 46:444-452.

5. Agüero-Torres H, Fratiglioni L, Guo Z, Viitanen M, von Strauss E, Winblad B: Dementia is the major cause of functional dependence in the elderly: 3-year follow-up data from a population-based study. Am J Public Health 1998, 88:1452-1456.

6. World Health Organization: World Health Report 2002 - Reducing Risks, Promoting Healthy Life. Geneva: World Health Organization; 2002.

7. Brookmeyer R, Johnson E, Ziegler-Graham K, Arrighi HM: Forecasting the global burden of Alzheimer's disease. Alzheimers Dement 2007, 3:186-191.

8. Fratiglioni $L$, De Ronchi D, Agüero-Torres H: Worldwide prevalence and incidence of dementia. Drugs Aging 1999, 15:365-375.

9. Mathers CD, Vos T, Lopez AD, Salomon J, Ezzati M: National Burden of Disease Studies: A Practical Guide. In Global Program on Evidence for Health Policy. 20th edition. Geneva: World Health Organization; 2001.

10. World Health Organization: World Health Report 2003. Shaping the Future. Geneva: World Health Organization; 2003.

11. Prince $M$ : The need for research on dementia in developing countries. Trop Med Health 1997, 2:993-1000.

12. Wimo A, Winblad B, Aguero-Torres H, von Strauss E: The magnitude of dementia occurrence in the world. Alzheimer Dis Assoc Disord 2003, 17:63-67.

13. Dementia Research Group: Methodological issues in population-based research into dementia in developing countries: a position paper from the 10/66 Dementia Research Group. Int J Geriatr Psychiatry 2000, 15:21-30.

14. Chandra V, Ganguli M, Pandav R, Johnston J, Belle SH, Ratcliff G, Ganguli M: Prevalence of Alzheimer's disease and other dementias in rural India: the Indo-US study. Neurology 1998, 51:1000-1008.

15. Hendrie HC, Osuntokun BO, Hall KS, Ogunniyi AO, Hui SL, Unverzagt FW, Gureje O, Rodenberg CA, Baiyewu O, Musick BS: Prevalence of Alzheimer's disease and dementia in two communities: Nigerian Africans and African Americans. Am J Psychiatry 1995, 152:1485-1492.

16. Statistics Korea: Population of Korea 2008. http://kosis.kr/eng/database/ database_001000.jsp?listid=B\&subtitle=\#jsClick. Accessed on Feb 282013.

17. Mathers C, Leonardi M: Global Burden of Dementia in the Year 2000: Summary of Methods and Data Sources. GBD 2000 Working Paper. Geneva: World Health Organization; 2000.

18. Alzheimer Disease International: World Alzheimer Report 2009. London: Alzheimer's Disease International; 2009:25-46.

19. Kim KW, Park JH, Kim MH, Kim MD, Kim BJ, Kim SK, Kim JL, Moon SW, Bae JN, Woo Jl, Ryu SH, Yoon JC, Lee NJ, Lee DY, Lee DW, Lee SB, Lee JJ, Lee JY, Lee CU, Chang SM, Jhoo JH, Cho MJ: A nationwide survey on the prevalence of dementia and mild cognitive impairment in South Korea. J Alzheimers Dis 2011, 23:281-291.

20. Cho MJ: Nationwide study on the prevalence of dementia in Korean Elders. Seoul: Seoul National University Hospital. Ministry of Health, Welfare, and Family Affairs; 2008:227.

21. Statistics Korea: Cause of death statistics 2008. http://kosis.kr/eng/database/ database_001000.jsp?listid=Z. Accessed on Feb 282013.

22. World Health Organization DISMOD-II. http://www.who.int/healthinfo/ global_burden_disease/tools_software/en/. Accessed on Feb 282013.

23. Barendregt JJ, Van Oortmarssen GJ, Vos T, Murray CJ: A generic model for the assessment of disease epidemiology: the computational basis of DisMod II. Popul Health Metr 2003, 1:4.

24. Lee JK, Yoon SJ, Do YK, Kwon YH, Kim CY, Park K, Kim YI, Shin YS: Disability weights for diseases in Korea. Korean J Prev Med 2003, 2:163-170.

25. Murray CJ, Lopez AD: The Global Burden of Disease: A Comprehensive Assessment of Mortality and Disability from Diseases, Injuries and Risk Factors in 1990 and Projected to 2020. Boston, MA: Harvard University Press; 1996:1-98.

26. Statistics Korea: 2008 Life Tables for Korea. http://kosis.kr/eng/database/ 456database_001000.jsp?listid=B\&subtitle=Population,\%20Household. Accessed on February 1, 2012.

27. Statistics Korea: Population projections 2010-2050. http://kosis.kr/eng/ database/database_001000.jsp?listid=B\&subtitle==\#jsClick. Accessed on Feb 282013

28. World Health Organization: Death and DALY Estimates for 2004 by Cause for WHO Member States. http://www.who.int/healthinfo/global_burden_disease/ estimates_country/en/index.html. Accessed on February 1, 2012.

29. Kinsella K, He W: An aging world: 2008. International Population Reports, P95/091. U.S. Census Bureau. Washington D.C: U.S. Government Printing Office; 2009.

30. Ott A, Breteler MM, van Harskamp F, Claus JJ, van der Cammen TJ, Grobbee DE, Hofman A: Prevalence of Alzheimer's disease and vascular dementia: association with education. The Rotterdam study. BMJ 1995, 310:970-973.

31. O'Connor DW, Pollitt PA, Hyde JB: The prevalence of dementia as measured by the Cambridge Mental Disorders of the Elderly Examination. Acta Psychiatr Scand 1989, 79:190-198. 
32. Evans DA, Funkenstein HH, Albert MS, Scherr PA, Cook NR, Chown MJ, Hebert LE, Hennekens $\mathrm{CH}$, Taylor JO: Prevalence of Alzheimer's disease in a community population of older persons. Higher than previously reported. JAMA 1989, 262:2551-2556.

33. Rocca WA, Bonaiuto S, Lippi A, Luciani P, Turtù F, Cavarzeran F, Amaducci L: Prevalence of clinically diagnosed Alzheimer's disease and other dementing disorders: a door-to-door survey in Appignano, Macerata Province, Italy. Neurology 1990, 40:626-631.

34. Dartigues JF, Helmer $C$, Letenneur L, Péres $K$, Amieva $H$, Auriacombe $S$, Orgogozo JM, Commenges D, Jacamin-Gadda H, Richard-Harston S, Delva F, Foubert-Samier A, Barberger-Gateau P: Paquid 2012: illustration and overview. Geriatr Psychol Neuropsychiatr Vieil 2012, 10:325-331.

35. Canadian Study of Health and Aging Working Group: Canadian study of health and aging: study methods and prevalence of dementia. Can Med Assoc J 1994, 150:899-913.

36. Fratiglioni L, Grut M, Forsell $Y$, Viitanen $M$, Grafström $M$, Holmén $K$, Ericsson K, Bäckman L, Ahlbom A, Winblad B: Prevalence of Alzheimer's disease and other dementias in an elderly urban population: relationship with age, sex, and education. Neurology 1991, 41:1886-1892.

37. Ueda K, Kawano H, Hasuo Y, Fujishima M: Prevalence and etiology of dementia in a Japanese community. Stroke 1992, 23:798-803.

38. Hasegawa K: The clinical issues of age-related dementia. Tohoku J Exp Med 1990, 161:29-38.

39. Yamada M, Sasaki H, Mimori Y, Kasagi F, Sudoh S, Ikeda J, Hosoda Y, Nakamura S, Kodama K: Prevalence and risks of dementia in the Japanese population: RERF's adult health study Hiroshima subjects. Radiation Effects Research Foundation. J Am Geriatr Soc 1999, 47:189-195.

40. Shibayama $\mathrm{H}$, Kasahara $\mathrm{Y}$, Kobayashi $\mathrm{H}$ : Prevalence of dementia in a Japanese elderly population. Acta Psychiatr Scand 1986, 74:144-151.

41. Jorm AF, Korten AE, Henderson AS: The prevalence of dementia: a quantitative integration of the literature. Acta Psychiatr Scand 1987, 76:465-479.

42. Hofman A, Rocca WA, Breteler MM BC, Clarke M, Cooper B, Copeland JR, Dartigues JF, da Silva Droux A, Hagnell O, Heeren TJ, Engedal K, Jonker C, Lindesay J, Lobo A, Mann AH, Moelsae PK, Morgan K, O'Connor DW, Sulkava R, Kay DW, Amaducci L, EURODEM Prevalence Research Group: The prevalence of dementia in Europe: a collaborative study of 1980-1990 findings. Eurodem Prevalence Research Group. Int J Epidemiol 1991, 20:736-748.

43. Sloane PD, Zimmerman S, Suchindran C, Reed P, Wang L, Boustani M, Sudha S: The public health impact of Alzheimer's disease, 2000-2050: potential implication of treatment advances. Annu Rev Public Health 2002, 23:213-231.

doi:10.1186/1471-2458-13-293

Cite this article as: Park et al: Burden of disease due to dementia in the elderly population of Korea: present and future. BMC Public Health 2013 $13: 293$

\section{Submit your next manuscript to BioMed Central and take full advantage of:}

- Convenient online submission

- Thorough peer review

- No space constraints or color figure charges

- Immediate publication on acceptance

- Inclusion in PubMed, CAS, Scopus and Google Scholar

- Research which is freely available for redistribution 